\title{
ИНФОРМАЦИОННЫЕ ТЕХНОЛОГИИ КОНТРОЛЯ УСПЕВАЕМОСТИ И КАЧЕСТВА ЗНАНИЙ ОБУЧАЮЩИХСЯ В УЧРЕЖДЕНИЯХ СРЕДНЕГО ПРОФЕССИОНАЛЬНОГО ОБРАЗОВАНИЯ
}

\section{INFORMATION TECHNOLOGIES \\ FOR MONITORING THE PROGRESS \\ AND QUALITY OF KNOWLEDGE OF STUDENTS IN SECONDARY VOCATIONAL EDUCATION INSTITUTIONS \\ I. Cherenkova \\ I. Kutlikova \\ O. Kishcinova}

Summary: The forms and methods of pedagogical control in the vocational education system, when teaching general education disciplines are presented. A set of modern forms and methods of pedagogical control have been determined. Information technology are considered to improve the existing forms of monitoring progress. The control results were recorded in the form of a binary matrix, followed by statistical processing. Based on the results of statistical processing, an analysis of the students progress have made, which allows the teacher to estimate the distribution of the number of students in accordance with the levels of knowledge assimilation; to evaluate the dynamics of students' indicators under various forms of control; to focus on different types of tasks and the form of control; introduce differentiated tasks.

Keywords: levels of cognitive activity, pedagogical control, preliminary control, current control, final control, binary matrix.

\author{
Черенкова Ирина Анатольевна \\ старший преподаватель, ФГБОУ ВО МГАВМИБ - МВА \\ имени К.И. Скрябина \\ Iri68na68@mail.ru \\ Кутликова Ирина Вениаминовна \\ старший преподаватель, ГБОУ ВО МГАВМИБ - МВА \\ имени К.И. Скрябина \\ ivk-b@yandex.ru \\ Кишкинова Ольга Алексеевна \\ старший преподаватель, ФГБОУ ВО МГАВМИБ - МВА \\ имени К.И. Скрябина \\ olga.19672015@yandex.ru
}

Аннотация: Представлены формы и методы педагогического контроля в системе профессионального образования при преподавании общеобразовательных дисциплин. Определен набор современных форм и методов педагогического контроля. Рассматриваются информационные технологии, позволяющие совершенствовать имеющиеся формы контроля успеваемости. Результаты контроля фиксировались в виде бинарной матрицы с последующей статистической обработкой. По результатам статистической обработки произведен анализ успеваемости испытуемых, что позволяет преподавателю оценить распределение количества обучающихся в соответствии с уровнями усвоения знаний; оценить динамику показателей обучающихся при различных формах контроля; сделать акцент на различные виды заданий и форму проведения контроля; внедрять дифференцированные задания.

Ключевые слова: уровни познавательной деятельности, педагогический контроль, предварительный контроль, текущий контроль, итоговый контроль, бинарная матрица.

К методам контроля относятся устный, письменный, практический, тестовый и рейтинговый контроль, зачет и экзамен. Эти методы контроля имеют как свои преимущества, так и недостатки.

Известно, что существуют различные формы контроля знаний учащихся: фронтальный, групповой, индивидуальный и взаимный контроль, самоконтроль, предварительный, текущий и итоговый контроль $[1,2]$.

Результативность контроля во многом зависит от умелого сочетания выбранных методов, средств и форм контроля, от содержания, организации и систематичности контроля, от его значимости в учебном процессе. При предварительном контроле знаний используются письменные ответы на вопросы и выполнение практических заданий разного уровня. При текущем контроле используются решение экспериментальных задач, диктанты, тестовые задания, проведение несложных опытов 
и исследований. При итоговом контроле - коллоквиум, зачет, экзамен, проводимые в устном, письменном и тестовом режимах [1].

Целесообразно комбинированное использование методов и форм контроля учебной деятельности. Например, физические или математические диктанты удобно использовать для закрепления понятийного аппарата (узконаправленность метода); при решении экспериментальных задач можно провести небольшое исследование, изменив некоторые первоначальные параметры (взаимодополняемость одного метода другим); реферат или доклад с презентацией способствует развитию познавательной деятельности, расширению кругозора обучающихся; чтение чертежей, графиков и схем способствует развитию умения анализировать графическую информацию.

В условиях внедрения информационных технологий в образовательный процесс большое значение имеет автоматизированное управление всеми аспектами учебного процесса. Информационные технологии контроля успеваемости могут использоваться как средство управления информацией об оценках, полученных традиционными способами, и быть представленными автоматизированными системами контроля качества знаний, включающих в себя диагностический, обобщающий и коррекционный модули [3].

Использование информационных технологий на этапе педагогического тестирования [4], которое является совокупностью методических и организационных мероприятий, обеспечивает подготовку и проведение стандартизованной процедуры измерения уровня подготовленности испытуемых, а также обработку и анализ результатов математическими методами.

При правильной организации учебного процесса, использующего различные методы и формы контроля обучения, достигается определенный уровень качества знаний.

Целями нашего исследования являлись:

1. Анализ результатов предварительного, текущего и итогового контроля обучающихся.

2. Наблюдение, выявление и фиксация количественных и качественных показателей обучающихся.

3. Проверка действенности методики статистической обработки результатов контроля учебных достижений обучающихся с помощью бинарной матрицы для динамичного учета результатов педагогического контроля, а также корректировки стратегии и тактики педагогической деятельности.

4. Внедрение бинарной матрицы для продуктивного контроля показателей успеваемости обучающихся и качества знаний в учреждениях среднего профессионального образования.
Методологическую основу исследования составили идеи и положения системного (Берталанди Л., Блауберг И.В., Ломов Б.Ф., Юдин Э.Г. и др.), деятельностного (Выготский Л.С., Занков Л.В., Давыдов В.В., Эльконин Д.Б. и др.) и компетентностно-ориентированного (Ефремова Н.Ф., Зимняя И.А, Хуторской А.В., Шадриков В.Д. и др.) подходов в изучении, описании и объяснении явлений образования.

Теоретической основой исследования являются взгляды Аванесова В.С., Беспалько В.П., Загвязинского В.И., Звонникова В.И., Кима В.С., Талызиной Н.Ф., Челышковой М.Б., и др. на понимание сущности, функций и принципов осуществления педагогического контроля, его различных форм и методов, используемых в современном учебном процессе.

Исследования проводились на базе Кинологического колледжа ФГБОУ ВО МГАВМиБ - МВА имени К.И. Скрябина преподавателями кафедры Информационных технологий, математики и физики с обучающимися 1 курса по дисциплине «Физика».

Наблюдение и фиксация учебных достижений и качества знаний обучающихся проводилось трижды: в начале обучения - входной контроль, в процессе обучения - текущий контроль, и в конце обучения - итоговый контроль.

По итогам выполненных заданий была составлена бинарная матрица с последующим анализом качества знаний обучающихся при входном, текущем и итоговом контроле.

Составление и анализ бинарной матрицы выполнялись с применением приложения MS Excel 2010 пакета MS Office 2010.

Обучающимся выдавался комплекс разноуровневых заданий, которые они должны были выполнить при входном, текущем и итоговом контроле. Комплекс таких заданий был составлен по В.П. Беспалько [1]:

1. ученический (начальный) уровень;

2. алгоритмический (средний уровень);

3. эвристический (достаточный уровень);

4. творческий (высокий уровень).

Каждый уровень считается достигнутым в том случае, если обучающийся успешно выполнил предложенные задания.

Для каждого уровня был рассчитан процент выполнения учащимися заданий по формуле [5]:

$(\mathrm{n} / \mathrm{N}) \cdot 100 \%$,

где $\mathrm{n}$ - число учащихся, успешно выполнивших задания; $\mathrm{N}$ - общее количество учащихся. 
Результаты предварительного контроля фиксировались в виде бинарной матрицы

$$
b_{i j}: b_{i j}=\left\{\begin{array}{l}
0, \text { если ответ неправильный } \\
1, \text { если ответ правильный }
\end{array},\right.
$$

где $i=\overline{1, n}, j=\overline{1, m}$, где $\mathrm{n}-$ количество испытуемых, $\mathrm{m}$ - количество заданий.

Алгоритм статистической обработки бинарной матрицы включает следующие этапы.

1. Ранжирование строк и столбцов матрицы в порядке убывания.

2. Нахождение количества правильных ответов (сумма единиц в столбце) на каждое задание $\left(\mathrm{R}_{\mathrm{i}}\right)$, количества неправильных ответов (сумма нулей в столбце) на каждое задание $\left(\mathrm{W}_{\mathrm{i}}\right)$, относительной частоты (доли) правильных ответов ( $\left.p_{\mathrm{i}}\right)$, относительной частоты (доли) неправильных ответов (q). Эти величины рассчитываются по формулам [5]:

$$
\begin{aligned}
& W_{i}=n-R_{i} \\
& p_{i}=R_{i} / n ; \\
& q_{i}=W / n
\end{aligned}
$$

3. Построение дискретного ряда результата контроля.

4. Анализ полученных результатов.

В начале учебного года был проведён предваритель- ный контроль. Контроль проводился в тестовой форме и включал вопросы и задачи из различных тем курса физики средней школы. В исследовании принимало участие 20 обучающихся. У каждого обучающегося был индивидуальный вариант из 10-ти заданий.

На первом шаге обработки было выполнено ранжирование строк и столбцов в порядке убывания.

Аналогично были построены бинарные матрицы по результатам текущего и итогового контроля.

Текущий контроль позволяет оценить те знания, умения и навыки, которыми обладает обучающийся в процессе изучения конкретной темы. Обучающимся предлагались задания различного уровня сложности. Десять заданий на отметку «3» и по пять заданий на отметки «4» и «5» (задания «повышенной трудности»). По экспериментальным данным были сформированы бинарные матрицы двух видов: на отметку «3» и на отметки «4» и «5».

При итоговом контроле обучающимся предлагалось выполнить 20 заданий.

Для подготовки обучающихся к текущему и итого-

Таблица 1

Бинарная матрица результатов предварительного контроля

\begin{tabular}{|c|c|c|c|c|c|c|c|c|c|c|c|}
\multirow{2}{*}{$\begin{array}{c}\text { Номер } \\
\text { обучаюегся }\end{array}$} & \multicolumn{10}{|c|}{ Номер задания } \\
\cline { 2 - 13 } & 1 & 2 & 3 & 4 & 5 & 6 & 7 & 8 & 9 & 10 & Итог \\
\hline 1 & 1 & 0 & 0 & 1 & 0 & 1 & 0 & 0 & 0 & 1 & 4 \\
\hline 2 & 1 & 0 & 1 & 0 & 0 & 1 & 1 & 0 & 0 & 1 & 5 \\
\hline 3 & 0 & 0 & 1 & 1 & 0 & 1 & 0 & 0 & 0 & 1 & 4 \\
\hline 4 & 1 & 1 & 1 & 1 & 0 & 1 & 0 & 0 & 0 & 0 & 5 \\
\hline 5 & 1 & 1 & 1 & 1 & 1 & 1 & 1 & 1 & 1 & 1 & 10 \\
\hline 6 & 0 & 0 & 0 & 0 & 0 & 1 & 0 & 1 & 1 & 1 & 4 \\
\hline 7 & 1 & 1 & 1 & 1 & 1 & 1 & 1 & 1 & 0 & 0 & 8 \\
\hline 8 & 0 & 0 & 1 & 0 & 0 & 1 & 0 & 0 & 1 & 0 & 3 \\
\hline 9 & 1 & 1 & 1 & 0 & 0 & 1 & 0 & 1 & 1 & 1 & 7 \\
\hline 10 & 0 & 1 & 1 & 0 & 0 & 1 & 0 & 0 & 0 & 1 & 4 \\
\hline 11 & 1 & 1 & 1 & 1 & 1 & 1 & 1 & 1 & 0 & 0 & 8 \\
\hline 12 & 1 & 0 & 1 & 1 & 1 & 1 & 1 & 0 & 0 & 0 & 6 \\
\hline 13 & 0 & 1 & 1 & 1 & 0 & 1 & 0 & 0 & 0 & 1 & 5 \\
\hline 14 & 0 & 0 & 1 & 1 & 0 & 1 & 1 & 0 & 1 & 0 & 5 \\
\hline 15 & 1 & 0 & 1 & 1 & 0 & 1 & 1 & 1 & 0 & 1 & 7 \\
\hline 16 & 0 & 0 & 1 & 1 & 0 & 1 & 0 & 0 & 0 & 0 & 3 \\
\hline 17 & 1 & 1 & 1 & 1 & 1 & 1 & 1 & 1 & 1 & 0 & 9 \\
\hline 18 & 0 & 1 & 1 & 1 & 1 & 1 & 1 & 0 & 1 & 1 & 8 \\
\hline 19 & 0 & 0 & 1 & 1 & 0 & 1 & 0 & 1 & 0 & 0 & 4 \\
\hline 20 & 1 & 1 & 1 & 0 & 0 & 1 & 0 & 1 & 1 & 0 & 6 \\
\hline
\end{tabular}


вому контролям, а также для развития умения самостоятельной работы целесообразно использовать такие методы, как проектная и исследовательская деятельность с использованием информационных технологий [6-8]. Проектно-исследовательская деятельность - это хороший путь развития как практических, так и творческих способностей обучающихся. Этот метод характеризуется высокой степенью самостоятельности, способствует формированию умения работы с информацией, помогает выстроить структуру своей деятельности, учит обобщать и делать выводы. Основная задача - приобретение навыков самостоятельной теоретической и практической работы, результаты которой могут быть представлены в виде рефератов, отчетов или докладов с презентацией, что способствует развитию и раскрытию у обучающихся творческого потенциала и успешному проведению итогового контроля $[8,9]$.

На основании полученных экспериментальных данных и обработки бинарных матриц были получены соответствующие результаты по количественной и качественной оценке динамики познавательной деятельности обучающихся (табл. 2). Как видно из приведённых данных, на начальном этапе обучения преобладает первый уровень усвоения. В ходе исследования наблюдался стабильный рост количества обучающихся, переходящих на более высокие уровни осуществления познавательной деятельности. Были выявлены следующие тенденции:

- на протяжении года обучения обучающиеся колледжа прикладывали усилия для совершенствования своих знаний, для своего личностного роста, что отразилось на увеличении числа обучающихся соответствующих творческому уровню познавательной деятельности;

- во время обучения у обучающихся проходил период психологической адаптации к новым условиям обучения; некоторые из них проходил этот период быстрее, некоторые медленнее, что также сказывалось на ходе и результатах их познавательной деятельности;

- некоторые обучающиеся быстрее других переходили на более высокие уровни освоения, применяя полученные ранее знания в новых ситуациях и совершенствуя их с помощью новых;

- увеличение численных показателей на третьем и четвёртом уровнях усвоения говорит о том, что обучающиеся проявляют интерес к учебной дисциплине, возрастает мотивация, между обучающимися наблюдалась конкуренция за право ответить на вопрос или выйти к доске.

Было отмечено следующее:

- предварительный контроль у многих обучающихся вызывает стресс, связанный с проведением письменного контроля;

- увеличивается процент самостоятельности с каждой проверочной работой, это связано с тем, что обучающиеся разбираются в учебном материале, меньше обращаются с вопросами к преподавателю;

- при итоговом контроле уменьшается количество обучающихся, которые отвлекаются, увеличивается ответственность, что является положительной предпосылкой для повышения уровня продуктивности познавательной деятельности;

- важным условием повышения качества познавательной деятельности является факт постепенного увеличения в ходе обучения количества обучающихся с положительными эмоциями во время проведения письменных работ.

Таблица 2

Результаты различных видов контроля (количественный критерий)

\begin{tabular}{|l|c|c|c|}
\multicolumn{1}{c|}{$\begin{array}{c}\text { Уровни усвоения } \\
\text { (по В.П. Беспалько) }\end{array}$} & $\begin{array}{c}\text { Предварительный } \\
\text { контроль }\end{array}$ & $\begin{array}{c}\text { Текущий } \\
\text { контроль }\end{array}$ & $\begin{array}{c}\text { Итоговый } \\
\text { контроль }\end{array}$ \\
\hline Ученический & $45 \%$ & $15 \%$ & $10 \%$ \\
\hline Алгоритмический & $30 \%$ & $30 \%$ & $10 \%$ \\
\hline Эвристический & $20 \%$ & $30 \%$ & $45 \%$ \\
\hline Творческий & $5 \%$ & $25 \%$ & $35 \%$ \\
\hline
\end{tabular}

Анализ результатов различных видов контроля обучающихся показал, что в процессе обучения целесообразно использовать различные методы и формы обучения: воспроизведение обучающимися усвоенной информации; применение имеющихся у них знаний, умений и навыков для решения нестандартных задач; поиск обучающимися современной, актуальной и объективной информации для своего самосовершенствования; применение проектной и исследовательской деятельности в самостоятельной работе.

В ходе исследования были выделены количественные и качественные показатели. В процессе обучения наблюдался рост количества обучающихся, переходящих на более высокие уровни познавательной деятельности. Отмечен рост количества обучающихся, соответствующих творческому уровню при переходе от предварительного контроля к итоговому, увеличивается их ответственность, самостоятельность, возрастает мотивация. Период психологической адаптации к новым условиям обучения проходил у всех по-разному, что сказывалось на ходе и результатах познавательной деятельности.

Показана целесообразность использования бинарной матрицы для динамичного учета результатов педагогического контроля, а также корректировки стратегии и тактики педагогической деятельности. 


\section{ЛИТЕРАТУРА}

1. Беспалько В.П. Слагаемые педагогической технологии / В.П. Беспалько. - М. : Педагогика, 2005. - 296 с.

2. Ким В.С. Тестирование учебных достижений : монография / В.С. Ким. - Уссурийск : Издательство УГПИ, 2007. - 214 с.

3. Болотова В.А. Система оценки качества российского образования / В.А. Болотова, Н.Ф. Ефремова // Педагогика. - 2006. - № 1. - С. $22-31$.

4. Ксензова Г Ю. Оценочная деятельность учителя : учебно-методическое пособие / Г.Ю. Ксензова. - М. : Педагогическое общество России, 1999. - 121 с.

5. Юсупова А.В. Современные технологии обучения и контроля знаний : учебное пособие / А.В. Юсупова, Г.В. Завада, А.Г. Фролов. - Казань, 2010.88 с.

6. Кутликова И.В. Использование интерактивной формы обучения и проектно-исследовательской деятельности в учебном процессе / И.В. Кутликова, 0.А. Кишкинова, И.А. Черенкова // Актуальные проблемы ветеринарной медицины, зоотехнии и биотехнологии : сб. науч. тр. - М., 2014 . - С.30-32.

7. Кутликова И.В. Место исследовательской работы студентов в учебном процессе / И.В. Кутликова, Ю.Л. Гордеева, И.А. Черенкова // Педагогический опыт: теория, методика, практика : матер. IV Междунар. науч.-практ. конф. 30 октября 2015 г. - Чебоксары, 2015. - Т. 1. № 3 (4). - С.185-186.

8. Олешкевич А А., Василевич Ф.И. Проблемы и перспективы фундаментального образования в ветеринарных ВУЗах / А.А. Олешкевич, Ф И. Василевич // Сборник тезисов по итогам Профессорского форума 2019 «Наука. Образование. Регионы». - Москва, 2019. - С. 146-148.

9. Ваганова 0.И. Оценка образовательных результатов бакалавров профессионального обучения / 0.И. Ваганова, 0.Е. Ермакова // Вестник Мининского университета. - 2015. - № 3 (11). - С. 14.

10. Костылев Д.С. Информационные технологии оценивания качества учебных достижений обучающихся / Д.С. Костылев, Л.И. Кутепова, А.В. Трутанова // Педагогические науки. - 2017. - Т.6. - №3(20). - С. 190-192.

\section{( Черенкова Ирина Анатольевна (Iri68na68@mail.ru), Кутликова Ирина Вениаминовна (ivk-b@yandex.ru), Кишкинова Ольга Алексеевна (olga.19672015@yandex.ru).}

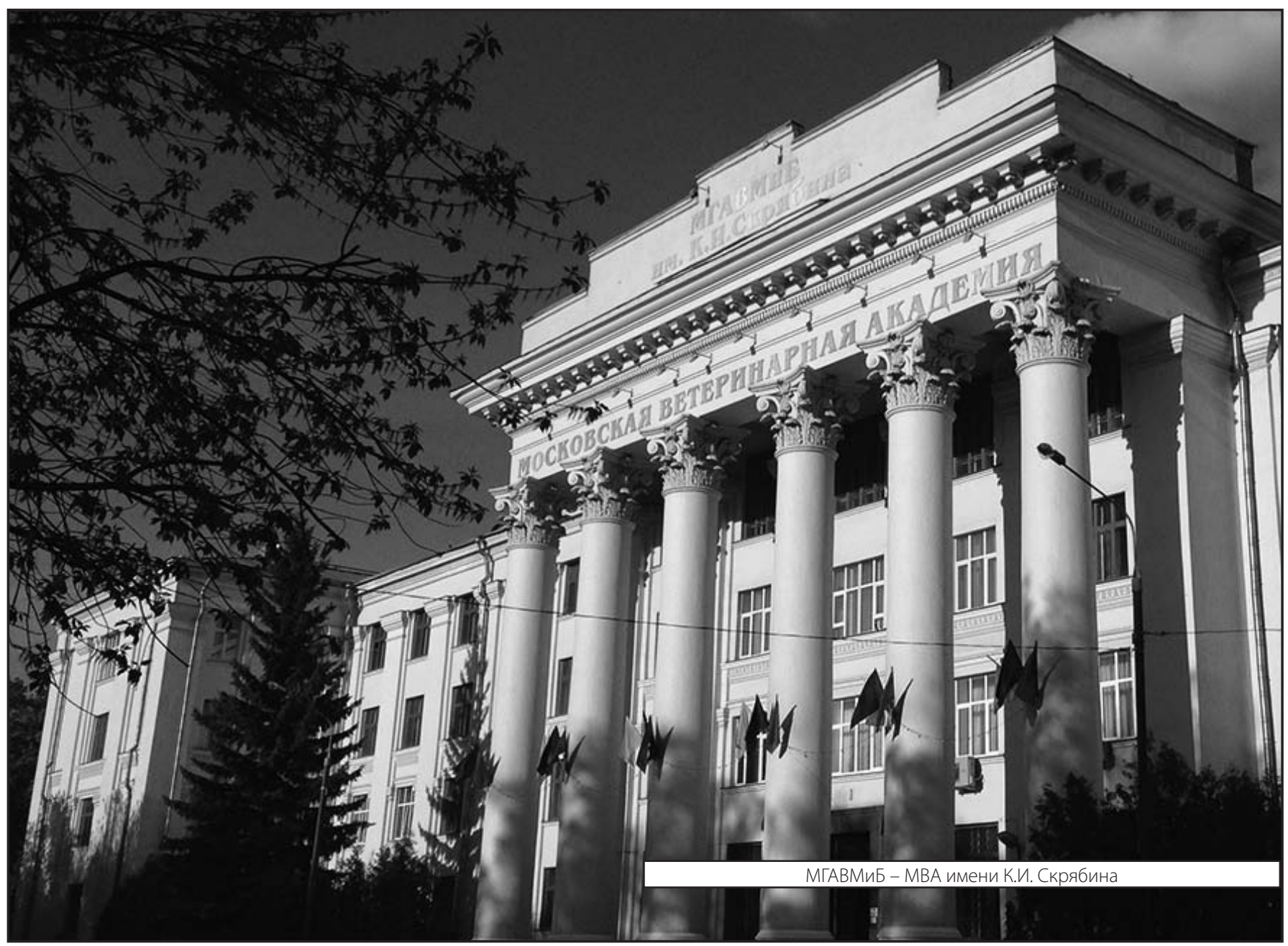

